\title{
For antagonists and mutualists: the paradox of insect toxic secondary metabolites in nectar and pollen
}

\author{
Philip C. Stevenson (1)
}

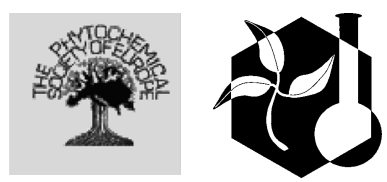

Received: 6 May 2019/Accepted: 19 August 2019/Published online: 30 August 2019

(C) The Author(s) 2019

\begin{abstract}
The plant kingdom produces an extraordinary diversity of secondary metabolites and the majority of the literature supports a defensive ecological role for them, particularly against invertebrate herbivores (antagonists). Plants also produce secondary compounds in floral nectar and pollen and these are often similar to those produced for defense against invertebrates elsewhere in the plant. This is largely because the chemical armoury within a single plant species is typically restricted to a few biochemical pathways and limited chemical products but how their occurrence in floral rewards is regulated to mediate both defence and enhanced pollination is not well understood. Several phytochemicals are reviewed here comparing the defensive function alongside their benefit to flower visiting mutualists. These include caffeine, aconitine, nicotine, thymol, linalool, lupanine and grayanotoxins comparing the evidence for their defensive function with their impacts on pollinators, their behaviour and well-being. Drivers of adaptation and the evolution of floral traits are discussed in the context of recent studies. Ultimately more research is required that helps determine the
\end{abstract}

P. C. Stevenson ( $₫)$

Royal Botanic Gardens, Kew, Richmond,

Surrey TW9 3AB, UK

e-mail: p.stevenson@kew.org

P. C. Stevenson

Natural Resources Institute, University of Greenwich, Chatham, Kent ME4 4TB, UK impacts of floral chemicals in free flying bees, and how compounds are metabolized, sequestered or excreted by flower feeding insects to understand how they may then affect the pollinators or their parasites. More work is also required on how plants regulate nectar and pollen chemistry to better understand how secondary metabolites and their defensive and pollinator supporting functions are controlled, evolve and adapt.

Keywords Bombus - Nectar chemicals $\cdot$ Bee pathogens - Crithidia bombi Caffeine $\cdot$ Nicotine . Pollinator specialization

\section{Introduction}

Animals and plants show adaptive selection for physical traits that optimize the efficiency of pollen transfer. Typically, adaptations augment greater fidelity or attention from flower visitors to a plant species that optimises pollen transfer between conspecific flowers; typically referred to as specialization (Brosi 2016). One of the most frequently cited examples of pollinator specialization is a physical adaptation; the extraordinarily long nectar spur of the moon orchid, Angraecum sesquipedale (Orchidaceae). This flower was predicted by Charles Darwin in 1862 to be pollinated by a moth with an equally long 
proboscis and 40 years later turned out to be the case with the discovery of Darwin's Sphinx moth Xanthopan morganii praedicta (Lepidotpera: Sphingidae) (Arditti et al. 2012). Numerous other examples exist where flower morphology has adapted to restrict nectar access to specialist taxa for example, Aconitum spp. (Ranunculaceae) (Thøstesen et al. 1996) and so garner greater pollinator focus and increase pollen transfer.

Phytochemicals also optimise pollination service in many plant species. For example, naïve honeybees show innate attraction to blue colours (Giurfa et al. 1995) which, in flowers, are produced by anthocyanins such as delphinidins (Katsumoto et al. 2007) or more stable metal chelated floral pigments such as<smiles>Cn1c(=O)c2c(ncn2C)n(C)c1=O</smiles>

Caffeine

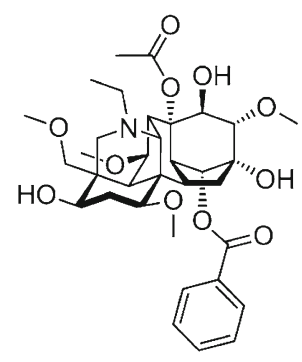

Aconitine

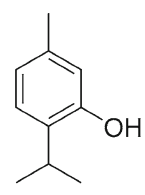

Thymol<smiles>CN1CCC[C@H]1c1cccnc1</smiles>

Nicotine

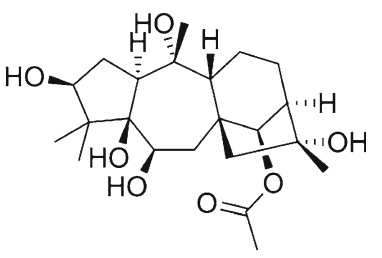

Grayanotoxin 1
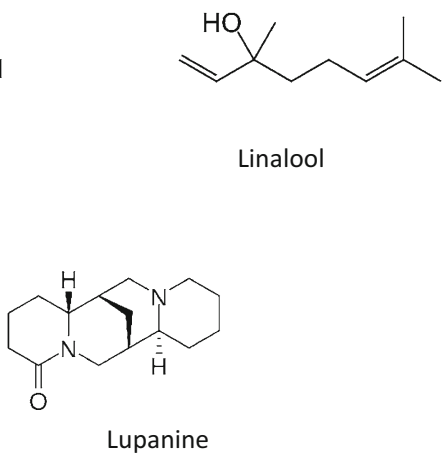

Fig. 1 Chemical structures of phytochemicals having a defensive role against insect antagonists but also various beneficial effects for pollinators commelinin from Commelina communis (Commelinacae) (Kondo et al. 1992). In some cases, the capacity to produce blue has driven highly specialised interactions based on mimicry and pseuodocopulation. The blue colour produced at the heart of the flower of Ophrys speculum (Orchidaceae) by cyanidin glycosides, predominantly the 3-O-(3"-O-malonylglucoside), is enhanced by surface structural features giving it a highly reflective quality that is much closer to the thorax of the mimicked insect (Vignolini et al. 2012).

Flower colours may even change with age or after pollination to dissuade further visitation although this may be dependent upon environmental context and is not common (Ruxton and Schaefer 2016). Pollinators are proposed to be the main selective agent driving the evolution of flower colour (Wang et al. 2013) and in concert with insect pheromone mimicry, illustrate further the extraordinary capacity of plants to mediate the services pollinators and present irresistible attraction for sexually active males. A notable example of floral odour mimicry is the production of a variety of pyrazines by hammer orchids such as Drakaea thynniphila (Orchidaceae) which very closely mimic the sex pheromone of the female Thynnid wasps (Agriomyia spp.) (Hymenoptera: Thynnidae) and prove irresistible to sexually active males (Bohman et al. 2014). So clearly floral chemistry is understood to play a significant role in optimising pollination service.

Floral phytochemistry has seen increased interest in recent years particularly around the chemistry of nectar and pollen and in part stimulated by Adler (2000) and the contemporary scientific popularity of pollination systems as standard bearers for healthy ecosystems. The most comprehensive phytochemical survey of nectar and pollen to date was published recently, analysing 31 cultivated and wild plant species from multiple sites and of different cultivars and established that pollen typically had the highest concentrations of secondary metabolites (PalmerYoung et al. 2019a, b). Since these plant compounds were typically reported to be associated with defence this finding was consistent with optimal defence theory and the importance of pollen as the male gamete but the occurrence in nectar presents an ecological paradox since this is the reward for flower visitors (Stevenson et al. 2017). And furthermore 
Table 1 Phytochemicals with dual ecological functions that protect against antagonists and optimise pollination services through attraction, behaviour mediation or improved pollinator health

\begin{tabular}{|c|c|c|c|}
\hline Compounds & $\begin{array}{l}\text { Defence function for } \\
\text { plants against antagonists }\end{array}$ & $\begin{array}{l}\text { Potential benefits to pollination or } \\
\text { pollinators }\end{array}$ & References \\
\hline Caffeine & $\begin{array}{l}\text { Inhibition of } \\
\text { phosphodiesterase and } \\
\text { increase in intracellular } \\
\text { cAMP in insects } \\
\text { Bioactive versus } \\
\text { Spodotera littoralis in } \\
\text { transformed tobacco } \\
\text { Toxic to honey bees }\end{array}$ & $\begin{array}{l}\text { Enhances memory for cues associated } \\
\text { with good food reward } \\
\text { Increases pollen deposition of Bombus } \\
\text { spp } \\
\text { Improves recruitment behaviours and } \\
\text { foraging focus } \\
\text { Reduces parasite load in bees }\end{array}$ & $\begin{array}{l}\text { Nathanson (1984), Kim et al. (2006), Detzel } \\
\text { and Wink (1993), Wright et al. (2013), } \\
\text { Thomson et al. (2015), Couvillon et al. } \\
\text { (2015), Richardson et al. (2015a, b), } \\
\text { Bernklau et al. (2019) }\end{array}$ \\
\hline Grayanotoxin 1 & $\begin{array}{l}\text { Provides defence against } \\
\text { Thrips major in } \\
\text { Rhododendron simsii } \\
\text { Related grayanotoxins } \\
\text { bioactive against } \\
\text { Lepidoptera } \\
\text { Toxic against honey bees } \\
\text { and Andrena scotica }\end{array}$ & $\begin{array}{l}\text { Selective toxicity to flower visitors } \\
\text { permits preferential nectar access to } \\
\text { Bombus spp }\end{array}$ & $\begin{array}{l}\text { Scott-Brown et al. (2016), Klocke et al. } \\
\text { (1991), Tiedeken et al. (2016), Tiedeken } \\
\text { et al. (2016) }\end{array}$ \\
\hline Aconitine & $\begin{array}{l}\text { Insect repellent activity to } \\
\text { Tribolium castaneum } \\
\text { Insect repellent to } \\
\text { Leptinotarsa } \\
\text { decemlineata }\end{array}$ & $\begin{array}{l}\text { Protection against nectar robbery by } \\
\text { Bombus terrestris with adaptation by } \\
\text { the pollinating bee species Bombus } \\
\text { hortorum }\end{array}$ & $\begin{array}{l}\text { Ulubelen et al. (2001), González-Coloma } \\
\text { et al. (2004), Barlow et al. (2017) }\end{array}$ \\
\hline Nicotine & $\begin{array}{l}\text { Reduced nectar robbery } \\
\text { by ants } \\
\text { Toxic to bees }\end{array}$ & $\begin{array}{l}\text { Reduced Crithidia bombi parasite loads } \\
\text { in Bombus spp }\end{array}$ & $\begin{array}{l}\text { Kessler and Baldwin (2007), Köhler et al. } \\
\text { (2012), Richardson et al. (2015a, b) }\end{array}$ \\
\hline Thymol & Toxic to Trichoplusia ni & $\begin{array}{l}\text { Reduces Crithidia bombi parasite loads } \\
\text { in Bombus impatiens } \\
\text { Bioactive against the parasite at } \\
\text { ecologically relevant concentrations }\end{array}$ & $\begin{array}{l}\text { Wilson and Isman (2006), Richardson et al. } \\
\text { (2015a, b), Palmer-Young et al. (2016) }\end{array}$ \\
\hline Linalool & $\begin{array}{l}\text { Repellent to Nilaparvata } \\
\text { lugens } \\
\text { Botanical insecticide }\end{array}$ & $\begin{array}{l}\text { Attracts Thrips major to Sambucus nigra } \\
\text { flowers for pollination service } \\
\text { Attracts natural enemies of herbivores }\end{array}$ & $\begin{array}{l}\text { Xiao et al. (2012), Isman (2006), Scott- } \\
\text { Brown et al. (2019), Yuan et al. (2008), } \\
\text { Xiao et al. (2012) }\end{array}$ \\
\hline
\end{tabular}

many allelochemicals occurring in plants are toxic or deterrent to bees (Detzel and Wink 1993).

One of the earliest reviews of secondary metabolites in nectar had postulated a defensive function for these compounds and noted that many of the compound groups occurring in nectar were also deterrent or toxic. Why would a flower secrete a toxin into the nectar since this is the reward for flower visitors that transfer pollen from one flower to a conspecific so provide a service to the plant (Baker 1977)? Subsequent reviews (Adler 2000; Irwin et al. 2014; Stevenson et al. 2017) have synthesised the role of nectar toxins around their various bioactivities-many of which have been convincingly argued to optimise pollen transfer between conspecific flowers. PalmerYoung et al. (2019a) reported that of over 100 compounds identified in pollen nectar and corolla tissue across the plant taxa, most were unique to a single species and that nectar and pollen chemistry always comprised of compounds that occurred in other plant tissues in the same species. Thus, if defence compounds occur in the foliage to protect against antagonists, they are likely to also occur in the nectar and pollen and be encountered by mutualists. While concentrations of secondary metabolites varied more in nectar than pollen the consistency with which they 
occur in nectar is nevertheless unexpected particularly since they are often cited as defensive against other invertebrates. Six examples are reviewed here that illustrate how plant secondary metabolites that have a reported defence function may have a dual role that is in conflict with its protective purpose (Fig. 1; Table 1). Existing knowledge gaps are also highlighted relevant to each compound.

Caffeine enhances bee memory and learning

Caffeine is a purine alkaloid that has established toxicity to invertebrates and is considered a potential natural biopesticide (Hollingsworth 2002). Its toxicity in insects is manifest by paralysing and intoxicating insects through inhibition of phosphodiesterase activity and increasing the intracellular levels of cyclic AMP (Nathanson 1984). It also inhibits feeding in the tobacco armyworm (Spodoptera litura) (Lepidoptera: Noctuidae) demonstrated through taste assays using leaf discs from a genetically transformed Nicotiana tabacum that biosynthesised caffeine (Uefuji et al. 2005; Kim et al. 2006). Most familiarly caffeine occurs at very high concentrations in coffee beans to protect against insect damage although the coffee berry borer (Hypothenemus hampei) (Coleoptera: Curculionidae), the major insect pest of coffee beans, has overcome this mechanism of defence through a symbiosis with a Pseudomonas species of gut symbiont that detoxifies caffeine for the host (CejaNavarro et al. 2015).

The role of caffeine in plant defence against invertebrate herbivores is therefore apparent so its occurrence in nectar, the food reward for invertebrate pollinators, was unexpected (Kretschmar and Baumann 1999) especially in the knowledge that it is also toxic to honeybees (Detzel and Wink 1993). Subsequent evaluation of the biological effect of caffeine against bees in learning and taste assays revealed more surprises. Firstly, caffeine is reportedly a feeding deterrent to honey bees in a dose dependent manner and it was detected in the nectar of several commercially important Citrus spp (Rutaceae) and Coffea spp. (Rubiaceae) (Wright et al. 2013). However, this was at concentrations that were below the bee's taste detection threshold. Secondly, bees fed caffeine at ecologically relevant concentrations during a learning experiment were three times more likely to recall a trait associated with a food reward than bees fed a control diet. This effect lasted for up to $72 \mathrm{~h}$ and was manifest through depolarisation of the membrane potential of Kenyon cells in the mushroom body of the bees brain where associative memory formation occurs indicating that this was a pharmacological effect acting on the brain directly (Menzel et al. 1980; Wright et al. 2013). Memory is an important attribute in generalist pollinators facilitating the rapid relocation of previously encountered and reliable sources of food (Menzel and Muller 1996). Wright et al. (2013) postulated that this enhancement of memory would provide an evolutionary advantage to the plant by manifesting enhanced fidelity to a caffeine containing reward in free flying bees and increased recruitment of nest mates. Shortly after Couvillon et al. (2015) demonstrated this prediction to be the case. How plants manage this dual role in defence and maximising attraction is quantitative as demonstrated by Thomson et al. (2015) who reported that artificial flowers containing caffeinated nectar at $10^{-5} \mathrm{M}$ received more pollen than flowers containing no caffeine or flowers containing artificial nectar with caffeine at $10^{-4} \mathrm{M}$. The behavioural change that enhances pollination is that caffeine enables bees to recall a trait or cue associated with food and be more likely to locate it, but this has yet to be demonstrated experimentally.

Ultimately it is conceivable that commercial bees utilised to maximise pollination services in horticulture could be trained to provision more efficient pollination services through exposure to the floral odours of target crops flowers while feeding on caffeinated food supplements; effectively training the bees to pollinate a target crop.

Caffeine occurs widely in the plant kingdom in at least 6 families of flowering plants. In floral tissues this includes Chamelia sinensis (Theaceae) (P. Stevenson unpubl.), Coffea spp. (Wright et al. 2013), Citrus spp. (Kretschmar and Baumann 1999), and Tilia spp. (Malvaceae) (Naef et al. 2007; Mathona et al. 2014). The flowers of these species are characterised by being small white and generally indistinct but with a strong aroma so these species may employ odour as the primary tool for attraction. This may suit pollination services by flower visitors susceptible to the effects of caffeine with a similar mechanism across these families. Koch and Stevenson (2017) suggest that this mechanism of increasing floral focus through enhanced memory for the odour associated with the 
food reward is so effective in Tilia spp. it may explain the phenomenon of dead bees under these trees-bees that overvalue the food source and continue to forage long after the tree has stopped producing nectar and ultimately run out of energy and drop to the ground and die since the nectar of Tilia spp. is reported to contain caffeine (Naef et al. 2007; Mathona et al. 2014).

More recently caffeine is reported to be a potential antimicrobial that could reduce disease load in honeybees caused by Nosema bombi (Dissociodihaplophasida: Nosematidae) (Bernklau et al. 2019) thereby offering an additional benefit to the pollinators that provide this most important service to plants. Although Richardson et al. (2015a, b) reported no effect against another parasite, Crithidia bombi (Trypanosomatida). The biological activity of nectar and pollen compounds against bee parasites is discussed in more detail below. The biological effects of related purine alkaloids including xanthine, theophylline and theobromine would be worthy of investigation.

\section{Diterpenoid nectar toxins in Rhododendron filter specialist pollinators}

Rhododendron (Ericaceae) is a large Genus of $>1000$ species found across the Northern hemisphere and into the Maleysian Peninsula and islands (Chamberlain et al. 1996). In the British Isles Rhododendrons are popular ornamentals but one species, $R$. ponticum subsp. baeticum, introduced from the Iberian Peninsula, has become highly invasive along with hybrids between $R$. ponticum and congenerics in parts of Britain (Milne and Abbott 2000). Invasive species may contribute to pollinator decline (Gonzalez-Varo et al. 2013) although considering the potential impacts only a few studies have investigated this (Stout and Morales 2009). Grayanoid diterpenes are the compounds responsible for the various biological activities attributable to mad honey and have been reviewed recently (Hanson 2016). Grayanoid diterpenes are tetracyclic diterpenoids with their biosynthetic origins in the isoprenyl pathway and the ecological function of these compounds is reportedly in defence. Rhodojaponin III, grayanotoxin III, and kalmanol were identified as the active components in flowers of the Chinese insecticidal plant, $R$. molle, with the most abundant compound rhodojaponin III, showing antifeedancy, growth inhibition and insecticidal activity against larvae of two Lepidoptera (Klocke et al. 1991). However, only one study by Scott-Brown et al. (2016) has reported grayanoid diterpenoids as a defense to an herbivore that targets Rhododendron. Grayanotoxin 1 (GTX I) was recorded in higher concentrations in young foliage of $R$. simsii and at a concentration that was biologically active as both a deterrent and as an entomotoxin against the glass house thrips Heliothrips haemorrhoidalis (Thysanoptera: Thripidae) (ScottBrown et al. 2016). The occurrence of grayanotoxins in nectar of Rhododendron is unexpected but has largely been assumed owing to its occurrence in honey and was, only very recently, reported directly from the nectar (Tiedeken et al. 2014). In this study GTX I was identified as the principal diterpene but did not have a deterrent effect against Bombus terrestris (Hymenoptera: Apidae) the buff-tailed bumble bee which is known to be a pollinator of the plant. However, later studies investigating the impact of an invasive plant species with toxic nectar in the British Isles on native fauna established that GTX I was both deterrent to and highly toxic to native honey bees Apis mellifera subsp. mellifera (Hymenoptera: Apidae) and a solitary mining species of bee Andrena scotica (Hymenoptera: Andrenidae) but Bombus terrestris remained unharmed (Tiedeken et al. 2016). The authors postulated that adaptation by the plant and the pollinator may have arisen to harness specialised foraging on this otherwise entomotoxic nectar and so secure the nectar reward for Bombus species which are the primary pollinator of R. ponticum in the British Isles. When an introduced species provides nectar containing invertebrate toxins poorly adapted pollinators that did not co-evolve with it could be intolerant of the effects (Callaway and Ridenour 2004). Further, this effect could serve to filter the most efficient pollinators-in this case Bombus spp.- - and may co-evolve rapidly in the introduced range of $R$. ponticum (Tiedeken et al. 2016). So GTX 1 provides Rhododendron with effective protection against antagonists and enhances pollination service by mutualists in the same plant. How this mechanism adapts in the introduced populations is discussed further below.

Grayanotoxins have been considered as candidates for botanical insecticides since they have activity against a range of pests insect species (Mei-Ying et al. 2015). Commercially produced B. terrestris are used increasingly by farmers to supplement pollination services-particularly in polytunnels and greenhouse 
crops such as tomatoes and strawberries. Since Bombus spp. are tolerant of grayanotoxins and these compounds have a wide-ranging activity against invertebrate antagonists it is possible they could provide candidates for bee friendly botanical insecticides.

Diterpene alkaloids in Aconitum spp. and nectar robbery

Species in the Genus Aconitum produce potent mammalian toxins with reports of human poisonings associated with the norditerpenoid alkaloids that occur in all plant parts (Kolev et al. 1996). As with grayanotoxins and caffeine the ecological function to the plant of these compounds is likely to be for defense against herbivory since several compounds of this class from Aconitum and related species have deterrent properties against insects (Ulubelen et al. 2001; González-Coloma et al. 2004). Flowers of Aconitum spp. are notable for having highly adapted nectaries on two long nectar spurs protected by a sepaloid hood or galea restricting nectar access to only long-tongued species of Bumble bee (Thøstesen et al. 1996). Despite these efforts to limit access to a few species of more forage focussed pollinators and increase the likelihood of pollen transfer to conspecific flowers, Aconitum flowers suffer from nectar robbery. Nectar robbing occurs when a hole is chewed through the corolla to access nectar that is otherwise unavailable via the route intended by the plants (Inouye 1980). However, this doesn't appear to come with any fitness cost to Aconitum (Utelli and Roy 2000). This can be explained because fewer than $10 \%$ of flower visits are by robbing species and only a small fraction of these visits result in a successful robbing event due to the occurrence of insect repellent norditerpenoids in nectar of Aconitum flowers (Barlow et al. 2017). These compounds vary in concentrations from one flower to the next and at the highest concentrations are too toxic even for the pollinator but importantly the robbing species of Bombus (B. terrestris in UK) are poorly adapted to their effects compared to the pollinating species which can tolerate concentrations of the nectar toxins that are 10 times higher than the robbing species.

Bee species may not be particularly sensitive to toxins in food (Wright et al. 2010; de Brito Sanchez et al. 2015) but adaptation to toxins differs among species since the short tongued species $B$. terrestris was more likely to be deterred by artificial food containing aconitine than a long-tongued specialist like $B$. hortorum and this may be related to short tongued species outcompeting long-tongued species for flowers with generalist pollinator syndrome.

So, again, the limited chemical armoury of Aconitum species serves both to protect the plant from antagonists such as folivores and nectar robbers while concurrently conserving the nectar in their morphologically adapted nectaries for long tongued species that can access the nectar trough the intended route, tolerate the toxins and pollinate the plant. It would be interesting to determine how widespread tolerance to these diterpene alkaloid toxins is among long-tongued species including B. gerstackerii the Aconitum specialist and how consistently intolerant short-tongued and potentially robbing species are.

Nectar phytochemistry and pollinator health

Diseases are a major biotic challenge for bees and can contribute to pollinator declines particularly in combination with other stressors including habitat loss, invasive species and pesticide exposure (Vanbergen et al. 2013). Bees transmit and acquire diseases on flowers, but flower phenology including chemistry may influence transmission and disease spread (Mcart et al. 2014; Koch et al. 2017). The role of plant species and variation in these traits is largely unexplored and may inform how disease transmission can be better managed (Adler et al. 2018). Flower chemistry can influence bee disease by killing bee pathogens and reducing transmission, and secondary metabolites in nectar and pollen could be active against gut parasites and reduce levels of infections in foraging adults or larvae (Koch et al. 2017). Indeed recent work has established that nectar phytochemicals are biologically active against Crithidia bombi gut parasites of Bombus impatiens in artificially inoculated animals (Richardson et al. 2015a, b). Several commercially available compounds known to occur in nectar and be relevant to foraging by Bombus spp. from earlier reports including the alkaloids, nicotine and anabasine, and the phenolic monoterpene thymol were tested in inoculated bees and shown to reduce levels of infection in test bees. This potential benefit to bees is in conflict with the knowledge that some of these compounds have established roles as defence 
compounds but since honeybees response to nicotine is nuanced when it is encountered it may serve to effect more frequent visits between flowers by pollinators (Köhler et al. 2012) and reduce the amount of nectar required to maintain successful pollen transfer by native pollinators (Kessler and Baldwin 2007; Kessler et al. 2008).

Thymol is a phenolic based essential oil component of many plants; most notably Thymus vulgaris (Lamiaceae), and has biological activity against a number of insects with scope for commercialisation as a biopesticide (Isman 2006; Wilson and Isman 2006) and can confer resistance to invertebrate antagonists. Richardson et al. (2015a, b) reported minor activity of this compound against Crithidia bombi in B. impatiens but tested only at concentrations found in honey. Thymol occurs in nectar in higher levels than in honey and is more active at this ecologically relevant concentration against $C$. bombi (Palmer-Young et al. 2016). So, thymol may have potential benefit for bees in a landscape setting for the provision of nectar but also with the added value of reducing disease incidence. Thymol also occurs in a wide range of species including T. vulgaris, a popular and commercially cultivated plant. Furthermore, thymol is less harmful to bees than some of the other compounds tested by Richardson et al. (2015a, b) which can be directly toxic to them (Köhler et al. 2012) or cause malaise behaviours and sublethal effects (Hurst et al. 2014; Oliver et al. 2015). However, thymol did not limit acquisition of parasites and any effects of thymol against $C$. bombi in isolation may reflect indirect hostmediated, effects of chronic thymol ingestion (Rothchild et al. 2018) so other more consistently effective compounds are required before we can envision medicinal plants for bees in field margins and flower strips. Most studies on the biological activity of nectar compounds against bee pathogens however have not investigated the fate of the metabolites so have not fully explained the chemical processes that might be influencing the effects. Testing compounds in vitro for example may provide some activities but these may not necessarily reflect the chemistry of the insect gut where metabolism of compounds could influence activity-for example glycosylation or methylation having effects on the bioactivity. Phytochemical analysis of the contents of the hindgut where C. bombi proliferate would be informative for some target compounds and evaluation of the parasite itself to understand the mechanisms of effects are required. More studies to investigate free flying bees would be welcome to determine if they can reduce their pathogen load or uptake when foraging on the flowers that produce bioactive compounds in nectar and would be informative for understanding their capacity to contribute to bee health or influence transmission.

Pollen chemistry and pollination

A priori, herbivore defense of pollen makes sense since this is the male gamete; vital plant tissue, so conforms to optimal defence theory as a priority for protection (McCall and Fordyce 2010; Cook et al. 2013). Little surprise then that the concentrations of secondary metabolites in pollen is typically one or two orders of magnitude greater than in nectar (PalmerYoung et al. 2019a, b). Again, the consistency of occurrence of secondary metabolites across tissue reveals that components occurring in pollen are invariably similar to those occurring elsewhere in the plant for defense. For example, the genus Lupinus includes several crop species such as Lupinus mutabilis (Leguminosae); a food crop cultivated in South America. Lupinus species produce several quinolizidine alkaloids including sparteine and lupanine which occur throughout the plant but notably in the seeds at very high concentrations ( $3 \%$ by weight) (Hatzold et al. 1983). Evidence suggests their primary function is to protect the plants from insect attack, because D-lupanine is toxic and repellent to insects including beneficial arthropods that feed on the herbivores (Emrich 1991; Kordan et al. 2012). More recently D-lupanine along with its 13-O-tigloyloxy, 13-O-angeloyloxy, 13-hydroxy and 4- $O$-hydroxy-13$O$-angeloyloxy derivatives have been found in pollen at concentrations in excess of $2 \mathrm{mg} \mathrm{g}^{-1}$ and although at these concentrations did not increase mortality in Bombus terrestris, a pollinating species for Lupins, they did cause experimental micro-colonies to produce fewer and smaller males which could have longer term colony and population impacts (Arnold et al. 2014). The function of toxins in pollen as a defence makes sense but to cause existential impacts on a key mutualist does not. In these experiments, insects were provisioned treated pollen with no choice and it is the choice that may provide a more effective experimental arena to understand how pollen defence chemistry functions. Bombus species were deterred from 
collecting saponin-containing pollen from two Dipsacus spp. (Caprifoliaceae) and pollen containing the highest levels of a saponin were less groomed off, meaning the bees carried more pollen for pollination (Wang et al. 2019). Some evidence exists for repellent and attraction to function together to optimise temporal visitation patterns of pollinators to coincide with stigma receptiveness and pollen maturation (ScottBrown et al. 2019). Thrips major Uzel (Thysanoptera: Thripidae) occurs abundantly on flowers of the common Elder (Sambucus niger L.) (Adoxaceae) (Raspudić et al. 2009). Thrips major is widely recognised as a flower damaging pest species (Moritz et al. 2004). However, when T. major was excluded from inflorescences of $S$. niger the flowers failed to produce fruit indicating a role in pollination through pollen feeding behaviour. Peak abundance of linalool, the major monoterpenoid in the headspace of the inflorescence, coincided with the highest numbers of adult thrips on flowers and is an attractive compound to T. major. Thrips declined in senescing flowers correlating with higher concentrations of the cyanogenic glycosides prunasin and sambunigrin in reproductive tissue which were deterrent to the thrips (Scott-Brown et al. 2019). Cyanogenic glycosides are well-established defence compounds for invertebrates (Zagrobelny et al. 2004). This work provides a fresh view of thrips as beneficial insects along with evidence of a mutualistic relationship between $T$. major and $S$. nigra highlighting the possibility that their value in food production maybe overlooked and their systematic control may have unintended negative consequences. So, while plant defence compounds in plants can function simply to protect it the mechanisms of protection may themselves mediate more effective pollination by flower visitors carrying more pollen to conspecific flowers in adapted species. Elsewhere linalool is a deterrent to colonisation of rice by the rice brown planthopper (Nilaparvata lugens) (Hemiptera: Delphacideae) indicating its function in some plant species in defense (Xiao et al. 2012). How pest species remain deterred by a single compound while mutualists remain attracted to the same compound remains unclear although Xiao et al. (2012) also report that linalool attracts natural enemies of the brown planthopper so it is possible that the deterrence in the brown planthopper could be through association with greater predation.

\section{Conclusions}

For decades scientific evidence has strongly supported the primary adaptive function of secondary metabolites in plants for defense against herbivory-especially against invertebrates. There are countless reports of the biological activity of plant extracts and compounds against insects (Isman and Grieneisen 2014) consolidating this view but surprisingly little on the effects of phytochemicals on pollinators. Understanding how traits associated with food reward and reward chemistry would help inform the ecology and evolution of plants and pollinators (Parachnowitsch and Manson 2015).

Here, examples have been review that review ecological functions that benefit the plant through maximizing pollen transfer by repelling less preferred pollinators, supporting heathier pollinators or enhancing their behaviour to deliver more efficient pollination. This compelling evidence for ecological functions based on these biological effects raises the question of what is driving adaptation in plants for secondary metabolites and how does adaptation to herbivory and pollination interact? Ramos and Schiestl (2019) argue that pollination and herbivory are both concurrent drivers of diversity and should be studied together. They showed that plants under selection by pollinators (bees) evolved increased floral attractiveness, but this was compromised by herbivores. Plants under selection from pollinators and herbivores evolved higher degrees of self-compatibility and autonomous selfing, as well as reduced herkogamy.

A similar question is considered across large spatial scales in Egan et al. (2016) who measured levels of the entomotoxic diterpenoids grayanotoxin I (GTX I) and GTX III in leaves and nectar of Rhododendron ponticum in its native and introduced ranges. As mentioned above, high concentrations of GTX I in young Rhododendron leaves provide defense against insects (Scott-Brown et al. 2016) so its primary role appears from this evidence to be defense. But GTX I is also toxic to some pollinating species when encountered in nectar including honeybees and a solitary mining bee species, (Andrena scotica) whereas another pollinator, Bombus terrestris remains unaffected (Tiedeken et al. 2014, 2016) suggesting adaptation by Bombus permitting exclusive access to nectar for the pollinator and specialist pollinator service for 
the flowers. Occurrence of GTX I, the most active against bees, was significantly lower or absent from nectar in introduced plants whereas GTX III-inactive against the bees-was similar across locations. The occurrence of nectar GTX was not affected by environmental variation, and considering the specificity of change to GTX I, and its differential toxicity to some bee species, its occurrence in the plant may have been influenced during invasion by interaction with herbivores or via pollinator-mediated selection owing to local populations of pollinators in the introduced range being poorly adapted to nectar toxins which in the native range serve to filter out preferred pollinators (Egan et al. 2016). A comprehensive survey of the genus and correlation of the presence of toxic nectar and generalist pollinator syndromes or absence of toxins and specialists' flowers may provide stronger evidence that GTX I serves to filter specialists.

Crop domestication can also drive down plant defenses reducing inherent resistance to herbivory and disease so may similarly affect secondary metabolites in nectar and pollen with consequences for pollinators. In Vaccinium corymbosum (Ericaceae), domestication altered plant chemistry of nectar and pollen, and reduced pollen chemical diversity. These changes included the antimicrobial caffeic acid ester 4-Ocaffeoylshikimic acid which could have implications for pollen protection because caffeic acid esters of cyclitols are established herbivore antagonists (Stevenson et al. 1993) but these compounds also protect Bombus impatiens against the gut pathogen Crithidia bombi at concentrations found in wild but not cultivated plants (Egan et al. 2018). This suggests that domestication changed floral traits with consequences for bee health and investigations of pollinator-dependent crops more generally are required to determine broader implications of domestication on floral chemistry associated with domestication (Egan et al. 2018). Further work to establish how chemical adaptation responds to pollinator needs and herbivore defense including spatially discreet studies of nectar secondary compounds to show how variation affects plant ecology is required along with a broader view of phytochemistry beyond antagonistic interactions, that integrates the consequences of chemically defended mutualist rewards. Ultimately many of the knowledge gaps would be filled with more work on free flying bees to understand in realistic ecological settings how these effects manifest (e.g., Singaravelan et al. 2005; Manson et al. 2013; Couvillon et al. 2015).

Acknowledgements Research undertaken by the author and reviewed here was produced originally alongside others who are gratefully acknowledged including Prof Geraldine A. Wright (Oxon) supported by BBSRC BB/I000968/1, Prof Lynn Adler (U Mass), Prof Rebecca Irwin (NCSU) and Dr. Evan PalmerYoung (UC Davis) National Science Foundation (NSF DEB1258096), United States Dept Agriculture USDA-AFRI 2013-02536, Dr. Paul Egan (SLU) and Prof Jane Stout (Trinity College) supported by the Science Foundation of Ireland and the Peter Sowerby Foundation grant to PS, and the author acknowledges the contributions of the many other collaborators.

Open Access This article is distributed under the terms of the Creative Commons Attribution 4.0 International License (http:// creativecommons.org/licenses/by/4.0/), which permits unrestricted use, distribution, and reproduction in any medium, provided you give appropriate credit to the original author(s) and the source, provide a link to the Creative Commons license, and indicate if changes were made.

\section{References}

Adler LS (2000) The ecological significance of toxic nectar. Oikos 91:409-420. https://doi.org/10.1034/j.1600-0706. 2000.910301.x

Adler LS, Michaud KM, Ellner SP et al (2018) Disease where you dine: plant species and floral traits associated with pathogen transmission in bumble bees. Ecology 99:2535-2545. https://doi.org/10.1002/ecy.2503

Arditti J, John E, Kitching IJ, Wasserthal LT (2012) 'Good Heavens what insect can suck it'-Charles Darwin, Angraecum sesquipedale and Xanthopan morganii praedicta. Bot J Linn Soc 169:403-432. https://doi.org/10. 1111/j.1095-8339.2012.01250.x

Arnold SEJ, Idrovo MEP, Arias LJL et al (2014) Herbivore defence compounds occur in pollen and reduce bumblebee colony fitness. J Chem Ecol. https://doi.org/10.1007/ s10886-014-0467-4

Baker HG (1977) Non-sugar chemical constituents of nectar. Apidologie 8:349-356. https://doi.org/10.1051/apido: 19770405

Barlow SE, Wright GA, Ma C et al (2017) Distasteful nectar deters floral robbery. Curr Biol. https://doi.org/10.1016/j. cub.2017.07.012

Bernklau E, Bjostad L, Hogeboom A et al (2019) Dietary phytochemicals, honey bee longevity and pathogen tolerance. Insects 10:1-12. https://doi.org/10.3390/insects10010014

Bohman B, Phillips RD, Menz MHM et al (2014) Discovery of pyrazines as pollinator sex pheromones and orchid semiochemicals: implications for the evolution of sexual deception. New Phytol 203:939-952. https://doi.org/10. 1111/nph.12800 
Brosi BJ (2016) Tansley insight pollinator specialization: from the individual to the community. New Phytol 210:1190-1194

Ceja-Navarro JA, Vega FE, Karaoz U et al (2015) Gut microbiota mediate caffeine detoxification in the primary insect pest of coffee. Nat Commun 6:1-9. https://doi.org/10. 1038/ncomms 8618

Chamberlain D, Hyam R, Argent G et al (1996) The genus Rhododendron its classification and synonymy. Royal Botanic Garden Edinburgh, Edinburgh

Cook D, Manson JS, Gardner DR et al (2013) Norditerpene alkaloid concentrations in tissues and floral rewards of larkspurs and impacts on pollinators. Biochem Syst Ecol 48:123-131. https://doi.org/10.1016/j.bse.2012.11.015

Couvillon MJ, Toufailia A, Butterfield TM et al (2015) Caffeinated forage tricks honeybees into increasing foraging and recruitment behaviors. Curr Biol. https://doi.org/10. 1016/j.cub.2015.08.052

de Brito Sanchez MG, Serre M, Avargues-Weber A et al (2015) Learning context modulates aversive taste strength in honey bees. J Exp Biol 218:949-959

Callaway RM, Ridenour WM (2004) Novel weapons: invasive success and the evolution of increased competitive ability. Front Ecol Environ 2(8):436-443

Detzel A, Wink M (1993) Attraction, deterrence or intoxication of bees (Apis mellifera) by plant allelochemicals. Chemoecology 4:8-18

Egan PA, Stevenson PC, Tiedeken EJ et al (2016) Plant toxin levels in nectar vary spatially across native and introduced populations. J Ecol 104:1106-1115. https://doi.org/10. 1111/1365-2745.12573

Egan PA, Adler LS, Irwin RE et al (2018) Crop domestication alters floral reward chemistry with potential consequences for pollinator health. Front Plant Sci 9:1-14. https://doi. org/10.3389/fpls.2018.01357

Emrich BH (1991) Acquired toxicity of the lupin aphid, Macrosiphum albifrons, and its influence on the aphidophagous predators Coccinella septempunctata, Episyrphus balteatus and Chrysoperla carnea. Z Pflanzenk Pflanz 98:398-404

Giurfa M, Nflfiez J, Chittka L, Menzel R (1995) Colour preferences of flower-naive honeybees. J Comp Physiol A 177:247-259

González-Coloma A, Reina M, Medinaveitia A et al (2004) Structural diversity and defensive properties of norditerpenoid alkaloids. J Chem Ecol 30:1393-1408. https://doi. org/10.1023/B:JOEC.0000037747.74665.0a

Gonzalez-Varo JP, Biesmeijer JC, Bommarco R et al (2013) Combined effects of global change pressures on animalmediated pollination. Trends Ecol Evol 28:524-530

Hanson JR (2016) From 'mad honey' to hypotensive agents, the grayanoid diterpenes. Sci Prog 99:327-334. https://doi.org/ 10.3184/003685016X14720691270831

Hatzold T, Elmadfa I, Gross R et al (1983) Quinolizidine alkaloids in seeds of Lupinus mutabilis. J Agric Food Chem 31:934-938. https://doi.org/10.1021/jf00119a003

Hollingsworth RG (2002) Caffeine as a repellent for slugs and snails. Nature 417:915-916

Hurst V, Stevenson PC, Wright GA (2014) Toxins induce "malaise" behaviour in the honeybee (Apis mellifera).
J Comp Physiol A. https://doi.org/10.1007/s00359-0140932-0

Inouye DW (1980) The terminology of floral larceny. Ecology 61(5):1251-1253

Irwin RE, Cook D, Richardson LL et al (2014) Secondary compounds in floral rewards of toxic rangeland plants: impacts on pollinators. J Agric Food Chem 62:7335-7344. https://doi.org/10.1021/jf500521w

Isman MB (2006) Botanical insecticides, deterrents, and repellents in modern agriculture and an increasingly regulated world. Annu Rev Entomol 51:45-66. https://doi.org/10. 1146/annurev.ento.51.110104.151146

Isman MB, Grieneisen ML (2014) Botanical insecticide research: many publications, limited useful data. Trends Plant Sci 19:140-145. https://doi.org/10.1016/j.tplants. 2013.11.005

Katsumoto Y, Fukuchi-mizutani M, Fukui Y et al (2007) Engineering of the rose flavonoid biosynthetic pathway successfully generated blue-hued flowers accumulating delphinidin. Plant Cell Physiol 48:1589-1600. https://doi. org/10.1093/pcp/pcm131

Kessler D, Baldwin IT (2007) Making sense of nectar scents: the effects of nectar secondary metabolites on floral visitors of Nicotiana attenuata. Plant J 49:840-854. https://doi.org/ 10.1111/j.1365-313X.2006.02995.x

Kessler D, Gase K, Baldwin IT (2008) Field experiments with transformed plants reveal the sense of floral scents. Science 321:1200-1202. https://doi.org/10.1126/science.1160072

Kim YS, Uefuji H, Ogita S, Sano H (2006) Transgenic tobacco plants producing caffeine: a potential new strategy for insect pest control. Transgenic Res 15:667-672. https:// doi.org/10.1007/s11248-006-9006-6

Klocke JA, Hu M, Choo S, Kubo I (1991) Grayanoid diterpene insect antifeedants and insecticides from Rhododendron molle. Phytochemistry 30:1797-1800

Koch H, Stevenson PC (2017) Do linden trees kill bees? Reviewing the causes of bee deaths on silver linden (Tilia tomentosa). Biol Lett 13:20170484. https://doi.org/10. 1098/rsbl.2017.0484

Koch H, Brown MJ, Stevenson PC (2017) The role of disease in bee foraging ecology. Curr Opin Insect Sci 21:60-67. https://doi.org/10.1016/j.cois.2017.05.008

Köhler A, Pirk CWW, Nicolson SW (2012) Honeybees and nectar nicotine: deterrence and reduced survival versus potential health benefits. J Insect Physiol 58:286-292. https://doi.org/10.1016/j.jinsphys.2011.12.002

Kolev ST, Leman P, Kite GC et al (1996) Toxicity following accidental ingestion of Aconitum containing Chinese remedy. Hum Exp Toxicol 15:839-842. https://doi.org/10. 1177/096032719601501008

Kondo T, Yoshida K, Nakagawa A, Kawai T, Tamura H, Gotoo T (1992) Structural basis of blue-flower colour development in flowerpetals from Commelina communis. Nature 358:515-5185

Kordan B, Dancewicz K, Wróblewska A, Gabryś B (2012) Intraspecific variation in alkaloid profile of four lupine species with implications for the pea aphid probing behaviour. Phytochem Lett 5:71-77. https://doi.org/10.1016/j. phytol.2011.10.003 
Kretschmar JA, Baumann TW (1999) Caffeine in Citrus flowers. Phytochemistry 52:19-23. https://doi.org/10.1016/S00319422(99)00119-3

Manson JS, Cook D, Gardner DR, Irwin RE (2013) Dose-dependent effects of nectar alkaloids in a montane plantpollinator community. J Ecol 101:1604-1612. https://doi. org/10.1111/1365-2745.12144

Mathona C, Edder P, Christen P, Bieri S (2014) Unexpected occurrence of caffeine in sleep-inducing herbal teas. Chim Int J Chem 68:705-709. https://doi.org/10.2533/chimia. 2014.705

Mcart SH, Koch H, Irwin RE, Adler LS (2014) Arranging the bouquet of disease: floral traits and the transmission of plant and animal pathogens. Ecol Lett 17:624-636. https:// doi.org/10.1111/ele.12257

McCall AC, Fordyce JA (2010) Can optimal defence theory be used to predict the distribution of plant chemical defences? J Ecol 98:985-992

Mei-Ying H, Klocke JA, Chiu S-F, Kubo I (2015) Response of five insect species to a botanical insecticide, Rhodojaponin III. J Econ Entomol 86:706-711. https://doi.org/10.1093/ jee/86.3.706

Menzel R, Muller U (1996) Learning and memory in honeybees: from behavior to neural substrates. Annu Rev Neurosci 19:379-404. https://doi.org/10.1146/annurev.ne.19. 030196.002115

Menzel R, Erber J, Masuhr T (1980) Localization of short-term memory in the brain of the bee, Apis mellifera. Physiol Entomol 5:343-358. https://doi.org/10.1111/j.1365-3032. 1980.tb00244.x

Milne RI, Abbott RJ (2000) Origin and evolution of invasive naturalized material of Rhododendron ponticum $\mathrm{L}$. in the British Isles. Mol Ecol 9:541-556

Moritz G, Mound LA, Morris DC GA (2004) Pest thrips of the world - an identification and information system using molecular and microscopial methods. In: CBIT, Univ. Queensland,CDROM. http://thripsnet.zoologie.uni-halle. de/key-server-neu/data/0a08090e-0e03-4a0e-8502070105080e05/media/Html/Thrips_major.htm. Accessed 26 Apr 2019

Naef R, Jaquier A, Velluz A, Bachofen B (2007) From the linden flower to linden honey-volatile constituents of linden nectar, the extract of bee-stomach and ripe honey. Perspect Flavor Fragr Res 1:31-40. https://doi.org/10.1002/ 9783906390475.ch3

Nathanson JA (1984) Caffeine and related methylxanthines: possible naturally occurring pesticides. Science 226:184-187

Oliver CJ, Softley S, Williamson SM et al (2015) Pyrethroids and nectar toxins have subtle effects on the motor function, grooming and wing fanning behaviour of honeybees (Apis mellifera). PLoS ONE. https://doi.org/10.1371/journal. pone.0133733

Palmer-Young EC, Sadd BM, Stevenson PC et al (2016) Bumble bee parasite strains vary in resistance to phytochemicals. Sci Rep. https://doi.org/10.1038/srep37087

Palmer-Young EC, Farrell IW, Adler LS et al (2019a) Chemistry of floral rewards: intra- and interspecific variability of nectar and pollen secondary metabolites across taxa. Ecol Monogr 89:1-23. https://doi.org/10.1002/ecm.1335
Palmer-Young EC, Farrell IW, Adler LS et al (2019b) Secondary metabolites from nectar and pollen: a resource for ecological and evolutionary studies. Ecology. https://doi. org/10.1002/ecy.2621

Parachnowitsch AL, Manson JS (2015) The chemical ecology of plant-pollinator interactions: recent advances and future directions. Curr Opin Insect Sci 8:41-46. https://doi.org/ 10.1016/j.cois.2015.02.005

Ramos SE, Schiestl FP (2019) Rapid plant evolution driven by the interaction of pollination and herbivory. Science 196:193-196

Raspudić E, Ivezić M, Brmež M, Trdan S (2009) Distribution of Thysanoptera species and their host plants in Croatia. Acta Agric Slov 93:275-283

Richardson LL, Adler LS, Leonard AS et al (2015a) Secondary metabolites in floral nectar reduce parasite infections in bumblebees. Proc R Soc B Biol Sci 282:20142471. https:// doi.org/10.1098/rspb.2014.2471

Richardson LL, Adler LS, Leonard AS et al (2015b) Secondary metabolites in floral nectar reduce parasite infections in bumblebees. Proc R Soc B 282:20142471. https://doi.org/ 10.1098/rspb.2014.2471

Rothchild KW, Adler LS, Irwin RE et al (2018) Effects of shortterm exposure to naturally occurring thymol concentrations on transmission of a bumble bee parasite. Ecol Entomol 43:567-577. https://doi.org/10.1111/een.12631

Ruxton GD, Schaefer HM (2016) Floral colour change as a potential signal to pollinators. Curr Opin Plant Biol 32:96-100. https://doi.org/10.1016/j.pbi.2016.06.021

Scott-Brown AS, Gregory T, Farrell IW, Stevenson PC (2016) Leaf trichomes and foliar chemistry mediate defence against glasshouse thrips; Heliothrips haemorrhoidalis (Bouché) in Rhododendron simsii. Funct Plant Biol 43:1170-1182. https://doi.org/10.1071/FP16045

Scott-Brown AS, Arnold SEJ, Kite GC, Farrell IW, Farman DI, Collins DW, Stevenson PC (2019) Mechanisms in mutualisms: a chemically mediated thrips pollination strategy in common elder. Planta 250(1):367-379

Singaravelan N, Ne'eman G, Inbar M, Izhaki I (2005) Feeding responses of free-flying honeybees to secondary compounds mimicking floral nectars. $J$ Chem Ecol 31:2791-2804. https://doi.org/10.1007/s10886-005-8394$\mathrm{Z}$

Stevenson PC, Anderson JC, Blaney WM, Simmonds MSJ (1993) Developmental inhibition of Spodoptera litura (Fab.) larvae by a novel caffeoylquinic acid from the wild groundnut, Arachis paraguariensis (Chod et Hassl.). J Chem Ecol 19:2917-2933. https://doi.org/10.1007/ BF00980592

Stevenson PC, Nicolson SW, Wright GA (2017) Plant secondary metabolites in nectar: impacts on pollinators and ecological functions. Funct Ecol. https://doi.org/10.1111/ 1365-2435.12761

Stout JC, Morales CL (2009) Ecological impacts of invasive alien species on bees. Apidologie 40:388-409

Thomson JD, Draguleasa MA, Tan MG (2015) Flowers with caffeinated nectar receive more pollination. Arthropod Plant Interact 9:1-7. https://doi.org/10.1007/s11829-0149350-z

Thøstesen AM, Olesen JM, Thostesen AM (1996) Pollen removal and deposition by specialist and generalist 
bumblebees in Aconitum septentrionale. Oikos 77:77. https://doi.org/10.2307/3545587

Tiedeken EJ, Stout JC, Stevenson PC, Wright GA (2014) Bumblebees are not deterred by ecologically relevant concentrations of nectar toxins. J Exp Biol 217:1620-1625. https://doi.org/10.1242/jeb.097543

Tiedeken EJ, Egan PA, Stevenson PC et al (2016) Nectar chemistry modulates the impact of an invasive plant on native pollinators. Funct Ecol 30:885-893. https://doi.org/ 10.1111/1365-2435.12588

Uefuji H, Tatsumi Y, Morimoto M et al (2005) Caffeine production in tobacco plants by simultaneous expression of three coffee N-methyltrasferases and its potential as a pest repellant. Plant Mol Biol 59:221-227. https://doi.org/10. 1007/s11103-005-8520-x

Ulubelen A, Meric,li A, Meric, li F et al (2001) Insect repellent activity of diterpenoid alkaloids. Phyther Res 15:170-171. https://doi.org/10.1002/ptr.688

Utelli A-B, Roy BA (2000) Pollinator abundance and behavior on Aconitum lycoctonum (Ranunculaceae): an analysis of the quantity and quality components of pollination. Oikos 89:461-470. https://doi.org/10.1034/j.1600-0706.2000. 890305.x

Vanbergen AJ, Garratt MP, Vanbergen AJ et al (2013) Threats to an ecosystem service: pressures on pollinators. Front Ecol Environ 11:251-259. https://doi.org/10.1890/120126

Vignolini S, Davey MP, Bateman RM et al (2012) The mirror crack'd: both pigment and structure contribute to the glossy blue appearance of the mirror orchid, Ophrys speculum. New Phytol 196:1038-1047

Wang H, Conchou L, Bessière JM et al (2013) Flower color polymorphism in Iris lutescens (Iridaceae): biochemical analyses in light of plant-insect interactions. Phytochemistry 94:123-134. https://doi.org/10.1016/j.phytochem. 2013.05.007

Wang X-Y, Tang J, Wu T et al (2019) Bumblebee rejection of toxic pollen facilitates pollen transfer. Curr Biol. https:// doi.org/10.1016/j.cub.2019.03.023

Wilson JA, Isman MB (2006) Influence of essential oils on toxicity and pharmacokinetics of the plant toxin thymol in the larvae of Trichoplusia ni. Can Entomol 138:578-589. https://doi.org/10.4039/N06-801

Wright GA, Mustard JA, Simcock NK et al (2010) Parallel reinforcement pathways for conditioned food aversions in the honeybee. Curr Biol 20:2234-2240

Wright GA, Baker DD, Palmer MJ et al (2013) Caffeine in floral nectar enhances a pollinator's memory of reward. Science 339:1202-1204. https://doi.org/10.1126/science.1228806

Xiao Y, Wang Q, Erb M et al (2012) Specific herbivore-induced volatiles defend plants and determine insect community composition in the field. Ecol Lett 15:1130-1139. https:// doi.org/10.1111/j.1461-0248.2012.01835.x

Yuan JS, Köllner TG, Wiggins G, Grant J, Degenhardt J, Chen F (2008) Molecular and genomic basis of volatile-mediated indirect defense against insects in rice. Plant $\mathrm{J}$ 55(3):491-503

Zagrobelny M, Bak S, Vinther A (2004) Cyanogenic glucosides and plant-insect interactions. Phytochemistry 65:293-306. https://doi.org/10.1016/j.phytochem.2003.10.016

Publisher's Note Springer Nature remains neutral with regard to jurisdictional claims in published maps and institutional affiliations. 